\title{
Estudio arqueométrico comparativo de muestras de pinturas con azul egipcio, procedentes de la tumba de Nefertari siglo XIII a.C. y del Balneum, termas romanas, siglos I a.C., I d.C.
}

\author{
A. J. CRIADO PORTAL ${ }^{1}$, L. GARCÍA SÁNCHEZ ${ }^{1}$, F. PENCO VALENZUELA ${ }^{1}$, A. J. CRIADO MARTíN'1, \\ J. A. MARTÍNEZ GARCÍÁ1, J. CHAMÓN FERNÁNDEZ ${ }^{1}$ y C. DIETZ².
}

\begin{abstract}
' Departamento de Ciencia de Materiales e Ingeniería Metalúrgica, Facultad de Ciencias Químicas, Universidad Complutense de Madrid (U.C.M.) ${ }^{2}$ Centro de Arqueometría y Análisis Arqueológico (C.A.I. AAA), Facultad de Geografía e Historia, Universidad Complutense de Madrid (U.C.M.)
\end{abstract}

\begin{abstract}
En el trabajo presentado se han estudiado dos muestras de pinturas con el mismo pigmento, azul egipcio, de distinta procedencia. Las diferencias entre ellas vienen causadas por la funcionalidad. En el caso de la tumba de Nefertari se trata de decorar estancias interiores excavadas en roca en las que no sufrirían deterioro alguno, dado que no se accedería a ese lugar nunca más. En el caso del Balneum se trata de pinturas que decoran ambientes muy húmedos y cálidos y que, además, deben resistir el deterioro derivado de la actividad humana en dichas termas.
\end{abstract}

Palabras clave: Azul Egipcio, Cuprorivaite, Pigmentos, Materiales Antiguos Egipcios, Pinturas.

Archaeometrical comparative study of paint samples with Egyptian Blue, from Nefertari’s tomb (XIII Century BC) and Balneum (Roman baths, First Century BC and AD).

In the present work have studied two samples with the same pigment, Egyptian Blue, but from different sources. The difference between them is caused by the functionality. In the case of Nefertari's tomb is decorating interior rooms carved into rock in which they would not suffer any damage since it does not accessed to that place anymore. In the case of Balneum's baths is decorating very warm and humid rooms, and should resist deterioration resulting from human activity during the use of these baths.

Keywords: Egyptian Blue, Cuprorivaite, Pigments, Ancient Egyptian Materials, Paints.

\section{1.- INTRODUCCIÓN}

El azul egipcio es una de esas historias de la química con un halo de misterio que le acompañó siempre desde los comienzos de su invención y utilización, en el IV milenio a.C., en el enigmático Egipto y, posiblemente, en los primeros albores de las civilizaciones de Mesopotamia.

En todas estas civilizaciones jugó un papel de primera clase como el color que simboliza el cielo azul, desde donde reina el dios Amón de los egipcios o los innumerables dioses del panteón mesopotámico: Marduk, Assur, etc. Esta tradición de asociar el azul a los dioses supremos de Egipto y Mesopotamia, es recogida por el mundo helenístico y transmitido a Grecia y a Roma. Zeus y Júpiter reinan sobre los demás dioses desde el cielo azul. Al desaparecer Roma, los pueblos germánicos y musulmanes, destierran este hermoso color azul brillante, que desaparece de la paleta de los pintores y decoradores para no renacer hasta la actualidad. Este hermoso color azul, el primer pigmento artificial sintetizado por el hombre, es relativamente fácil de obtener, como veremos más adelante, y de una estabilidad excelente ante la luz solar y los agentes medioambientales más agresivos.
En los primeros momentos de su invención, el pigmento azul alternativo utilizado, provenía de sustancias minerales naturales, como: la azurita, un carbonato hidratado de cobre azul oscuro intenso que, desgraciadamente, ennegrece con el tiempo debido a la acción de la luz solar y, también, el lapislázuli triturado, un mineral bellísimo semiprecioso; además de otras sales de cationes coloreados, poco estables frente a la acción de la luz solar y de los agentes agresivos medioambientales.

Durante miles de años, este azul egipcio, fue el pigmento que decoró las tumbas reales y nobles egipcias, mesopotámicas y sus bellísimas construcciones religiosas y civiles; y lo mismo ocurrió en Grecia y Roma. Finalmente, desapareció, aunque existen numerosas opiniones que sustentan que ha sido utilizado en algunas ocasiones posteriores de la mano de inquietos maestros como, por ejemplo, Leonardo da Vinci. Si nos fijamos en su majestuoso retrato de "La Gioconda", veremos que los azules del paisaje del fondo de este maravilloso cuadro, están en distintos estados de conservación. Algo consustancial al gran maestro toscano, 
que convertía en largos y misteriosos experimentos todas sus creaciones, lo que no siempre fue positivo ya que, en algunos casos, fue la causa de su ruina, como ocurrió con su "Santa Cena", "La Batalla de Anghiari" o el famosos caballo para la estatua ecuestre de Ludovico el Moro en Milán. Pues bien, el lado derecho del cuadro de "La Gioconda" presenta un colorido azul precioso, vivo y brillante; mientras que, el lado izquierdo ha sufrido un fuerte ennegrecimiento. Siempre en el campo de las hipótesis y, como admiradores del maestro Leonardo, pensamos, al igual que otros muchos colegas, que si se analizaran esos colores mediante Difracción de Rayos- $X$, se podría comprobar que en el lado derecho utilizó azul egipcio mientras que, en el lado izquierdo, el color natural azurita. Piénsese que, en el Renacimiento italiano, se tradujo la obra del ingeniero militar y arquitecto romano Vitrubius quien, entre otras cosas, transmite muchas recetas para la fabricación de pigmentos de color usados en la Roma del siglo I a.C. y posterior. Entre otras recetas describe, minuciosamente, la fabricación del azul egipcio. Es frívolo pensar que, el gran maestro Leonardo, no tuvo la curiosidad de leer los libros de Vitrubius, un hombre de espíritu parecido al suyo; aunque no tan polifacético. Si a esto se le une su disposición a la experimentación, podemos imaginar que el maestro pudo haber hecho una incursión en el enigmático y antiguo azul egipcio.

En esta publicación vamos a exponer algunos de los resultados obtenidos, por este grupo de investigación, acerca de este pigmento y su utilización en dos épocas históricas brillantes y distantes en el tiempo y en el espacio. Una serie de las muestras estudiadas pertenece a la tumba QV66 del Valle de las Reinas (Queen Valley) de Egipto. En particular, fueron recogidas en la cámara del sarcófago de la inteligente y bellísima reina Nefertari-Merienmut, la esposa favorita y adorada del más grande de los faraones de Egipto, Ramsés II, de la XIX Dinastía (siglo XIII a.C.). Es la tumba más hermosa e increíble del Valle de las Reinas. La distribución y las pinturas murales son espléndidas. Los mensajes y las oraciones representadas en ellas son muy detallados, claros y exhaustivos, con la intención de que, la reina Nefertari, no se perdiera en su camino hacia el más allá a través de la muerte. Parece como si, Ramsés II se hubiera asegurado, tanto del acierto en el viaje de la amada esposa Nefertari como en dejarlo muy claro y explícito para seguirlo él después de su muerte, a la búsqueda de su enigmática, inteligente y bellísima Nefertari, a la que tanto amó y admiró en vida.

Las otras muestras proceden del Balneum (termas romanas) de Cerro Muriano (Córdoba), de época de transición republicana a alto-imperial, en tiempos de Octavio Augusto y Tiberio (siglos I a.C. y I d.C.). Se trata de unas termas excavadas parcialmente, que se situaban en el centro minero-metalúrgico de Cerro Muriano, regentado, por entonces, por el poderoso y riquísimo Sexto Mario, envidia del propio emperador Tiberio, que deseaba tanto su riqueza como a su bellísima hija que, hilando una escabrosa historia acerca del incesto de este potentado con su hija, lo condenó a ser arrojado desde la Montaña Tarpeya; pasando sus propiedades al emperador y no al Senado y, cómo no, quedando la bellísima hija a su custodia personal. Lo que no pudo Tiberio es arrebatarle la fama a su envidiado y odiado Sexto Mario, ya que desde entonces, aquella extensa sierra pasó a llamarse Mariánica en su honor. Posteriormente derivó a Sierra Morena.
En esta dirección del azul egipcio, se ha continuado otra línea de investigación que ha consistido en la síntesis de azul egipcio, según diferentes vías:

- $\quad$ siguiendo el método de Marcus Vitrubius Polio.

- siguiendo el posible método empleado en la XIX Dinastía inaugurada con Ramsés II.

- $\quad$ siguiendo, también, el método que creemos empleó la Hispania romana.

Con todos ellos se han obtenido resultados óptimos en todo semejantes a los de procedencia arqueológica. Estos resultados serán publicados próximamente.

Entrando ya en la materia arqueométrica de este artículo, hay que señalar que el azul egipcio es un filotetrasilicato de calcio y cobre obtenido artificialmente con mezcla de cuarzo, carbonato de calcio, óxidos de cobre o carbonatos de cobre (incluso cobre metálico) y carbonato sódico, calentándola a $850^{\circ} \mathrm{C}$ durante 24 horas (1-9). Otros autores proponen otras mezclas, pero siempre con los mismos componentes, aunque en compuestos químicos diferentes, como en la siguiente mezcla: una parte de $\mathrm{CaO}$ (cal viva), otra de $\mathrm{Cu}$ (metálico en virutas), cuatro partes de $\mathrm{SiO}_{2}$ (cuarzo) y un $10 \%$ de $\mathrm{Na}_{2} \mathrm{CO}_{3}$ (carbonato sódico), como fundente; calentando la mezcla a $850^{\circ} \mathrm{C}$ durante 24 horas (10-11).

La descripción más detallada de las que nos ha transmitido la historia antigua es de Marcus Vitrubius Polio (siglo I a.C.), ingeniero y arquitecto del ejército romano bajo el mando de César y Octavio Augusto. En su libro "De Architectura" (Libro VII,11), en los párrafos dedicados a "Del azul y el amarillo", describe la fabricación del azul egipcio, de la siguiente forma, según se hacía en aquel tiempo en la ciudad de Alejandría (Egipto):

“... se tritura arena (cuarzo y carbonato cálcico) con flor de sal mineral (carbonato sódico), formando una mezcla tan fina como la harina, se revuelve bronce de Chipre (cobre con algo de estaño), limado a partir de gruesas láminas, hasta que se forme una masa compacta; después, frotando las manos se van haciendo unas pelotitas que, una vez bien apretadas, se pondrán a secar. Cuando estén perfectamente secas, se colocan en una orza de barro, que introduciremos dentro de un horno: una vez que se haya secado conjuntamente el metal y la arena, gracias a la elevada temperatura del fuego, se produce un intercambio de sus propios vapores con la consiguiente eliminación de sus propiedades.

A causa de la fuerza del fuego, se consumen sus características originales y adquieren un color azul".

De esta manera nos cuenta él en su libro que este era el método que se utilizaba en Alejandría (Egipto) para fabricar el azul y que, un tal Vestorio trajo a la Península Itálica y organizó su fabricación en Puzol.

El denominado azul egipcio se corresponde con el muy escaso mineral natural "cuprorivaite". Fue utilizado, desde muy antiguo en Egipto y Mesopotamia, pasando después a Grecia y Roma (9-11), perdiéndose su uso con el final del Imperio Romano. Se ha constatado su presencia en las tumbas reales de Ur del tercer milenio a.C. (2500 a.C.) (13), y en Egipto a comienzos del III milenio a.C. (1). Hay indicios para remontar la existencia de este pigmento artificial a finales del IV milenio a.C. (14).

Desde un principio se utilizó como pigmento para las pinturas decorativas, en las tumbas y otros objetos artísticos 
(13-16), por su fuerte color azulado y su estabilidad frente a los agentes ambientales $(1,4-7,17-18)$. Así mismo, fue usado para otras aplicaciones como, el teñido de tejidos y maquillajes, hasta el final del Imperio Romano (10-12,19).

Esta investigación va dirigida a un estudio comparativo entre el uso de pinturas murales en el Egipto antiguo y en el ámbito del Imperio Romano. Es importante tener en cuenta que la mayor parte de las pinturas decorativas murales egipcias se realizaron en el interior de las tumbas; mientras que, en la antigua Roma, estas pinturas se realizaban para decorar las paredes de las casas, tanto interiores como exteriores, pudiéndose, en el caso romano, limpiar por lavado las interiores y quedar expuestas al medio ambiente las exteriores. Por el contrario, las pinturas egipcias iban destinadas a decorar sus bellísimas tumbas, quedando para siempre en interiores cerrados.

Las muestras a estudiar pertenecen a la tumba de la reina Nefertari-Merienmut, esposa favorita del faraón Ramsés II, de la XIX dinastía (siglo XIII a.C.) y, al Balneum (termas romanas del Mons Marianus) de Cerro Muriano (Córdoba) (siglos I a.C.-I d.C.), de época de Octavio Augusto a Tiberio.

La tumba de Nefertari es la QV66 (Queen Valley) en el Valle de las Reinas. Sin duda, es la más hermosa de todas. Se cerró con su muerte en 1262 a.C. La eflorescencia de sales del lecho rocoso de la tumba, a causa de las corrientes de agua subterráneas, terminaron por desconchar y arruinar algunas de las pinturas que cubren techos y paredes de forma exhaustiva. En la década de los 80 del siglo XX, fue restaurada por The Getty Conservation Institute en colaboración con el Consejo Supremo de Antigüedades de Egipto (9, 14-16). Permaneció cerrada unos años y, de nuevo, ha sido abierta al público que puede visitarla en grupos de 10 personas, en períodos de 10 minutos de duración máximo. Las muestras examinadas por este grupo de investigación son de la QV66 y pertenecen a desconchados de las paredes de la Cámara del Sarcófago (Figura.1). Se obtuvieron para su estudio, a través del Consejo Supremo de Antigüedades de Egipto.

Las muestras de azul egipcio del Balneum (termas romanas) de Cerro Muriano (Córdoba), fueron recogidas, junto con algunas piezas metálicas y cerámicas durante las excavaciones de 1999 y 2002, dirigidas por F. Penco Valenzuela (Figura.2) (21-23).

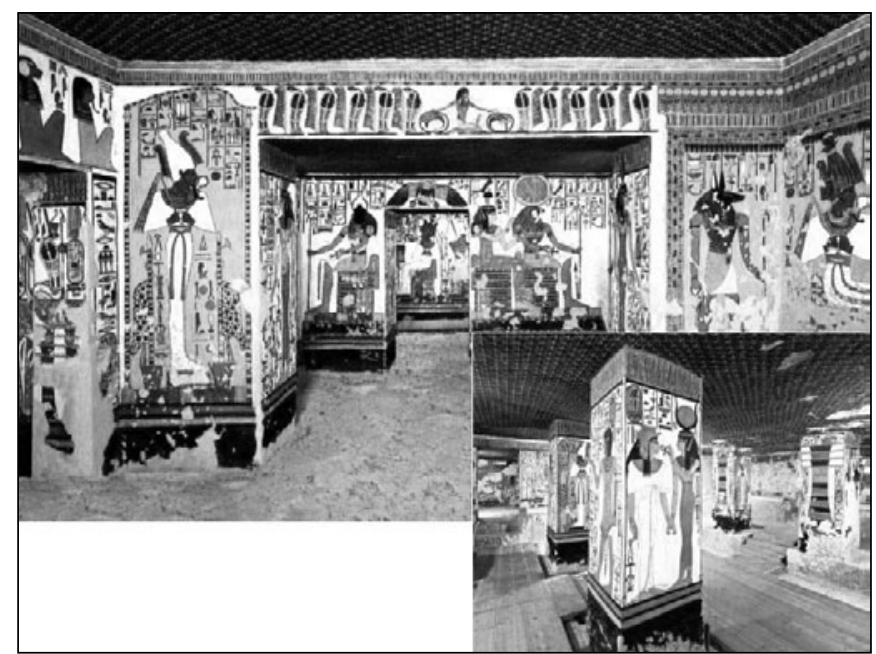

Figura.1: aspecto de las pinturas que cubren paredes y techo de la cámara funeraria de la QV66.
El objetivo principal de esta investigación fue encontrar las posibles diferencias, tanto en la pintura: pigmento, aglutinante y carga, como en los morteros de enlucido de las paredes (36, $37,38)$.

\section{2.- MATERIALES Y MÉTODOS}

Las muestras, en ambos casos, descascarilladas de las paredes, han sido estudiadas con el objetivo de ver las diferencias entre el pigmento egipcio y el romano, así como el modo de ejecutar la técnica de pintar.

Las muestras estudiadas fueron embutidas en resina de dos componentes Résine Mécaprex KM-U de Presi y, posteriormente, desbastadas y pulidas convencionalmente en papeles de desbaste de Buehler de grano 120[20], 270, 320 y 600, y paño de pulir de Buehler con alúmina $\alpha(0.3 \mu \mathrm{m})$ de Buehler. Las operaciones se realizaron correcta y eficazmente, a pesar de la naturaleza aparentemente frágil de las muestras, aunque bien consolidadas en la resina utilizada. Sin ataque químico se las secó convenientemente en estufa a $35^{\circ} \mathrm{C}$, durante dos horas.

Se observaron mediante Microscopía Óptica Convencional y, para la Microscopía Electrónica de Barrido con análisis EDS-EDX (Análisis Elemental Cualitativo por Dispersión de Energías) incorporado, se las depositó un metalizado de grafito de $20 \mathrm{~nm}$ de espesor, durante 1 minuto.

La identificación de los pigmentos, y de los demás compuestos presentes en el aglutinante y mortero soporte, se llevó a cabo mediante Difracción de Rayos-X y análisis EDSEDX.

\section{3.- RESULTADOS Y DISCUSIÓN}

Para llevar a cabo el objetivo principal de esta investigación se han utilizado las capas de pintura y de mortero de ambos casos.

En la tumba de Nefertari-Merienmut y en las termas de Cerro Muriano, la difracción de Rayos- $X$ ha identificado el pigmento de la capa de pintura como un filotetrasilicato de cobre y calcio (Figura.4), denominado en la literatura internacional como azul egipcio (26-35). En ambos casos, se

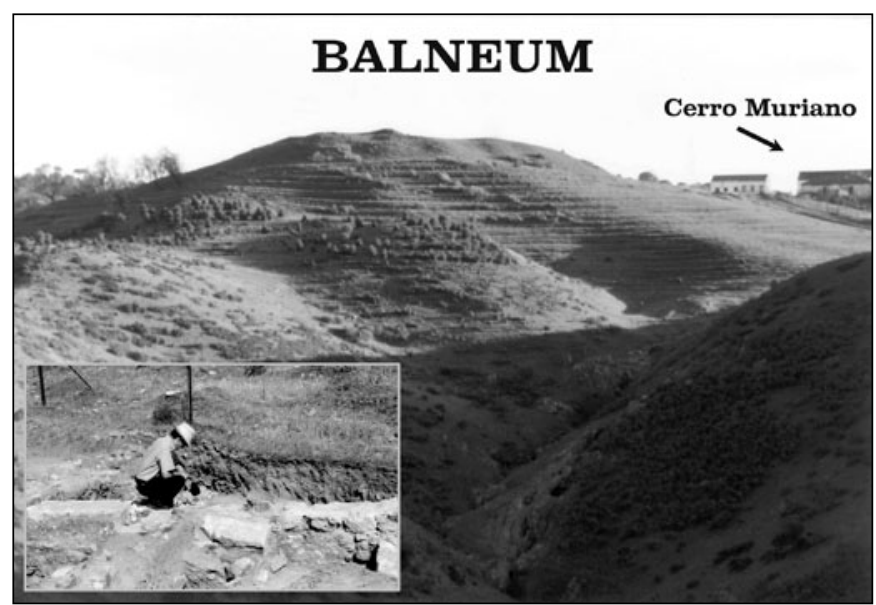

Figura.2: Vista de la zona de excavación del Balneum (Cerro Muriano, Córdoba). En la parte inferior izquierda, detalle de los inicios de la excavación. 
trata de un tetrasilicato de calcio y cobre sintético, el pigmento artificial más antiguo conocido.

Identificado el pigmento, que no es otro en ambos casos que el azul egipcio, analizamos los demás resultados, siguiendo una secuencia lógica y comparativa:

\section{1.- Muestra de la tumba de Nefertari- Merienmut:}

1.Nefertari Pintura (Capa de pintura):

- aglutinante.

- carga.

1.Nefertari Mortero (Capa de mortero):

- aglutinante.

- carga

1.Nefertari Pared (Soporte: material de la pared).

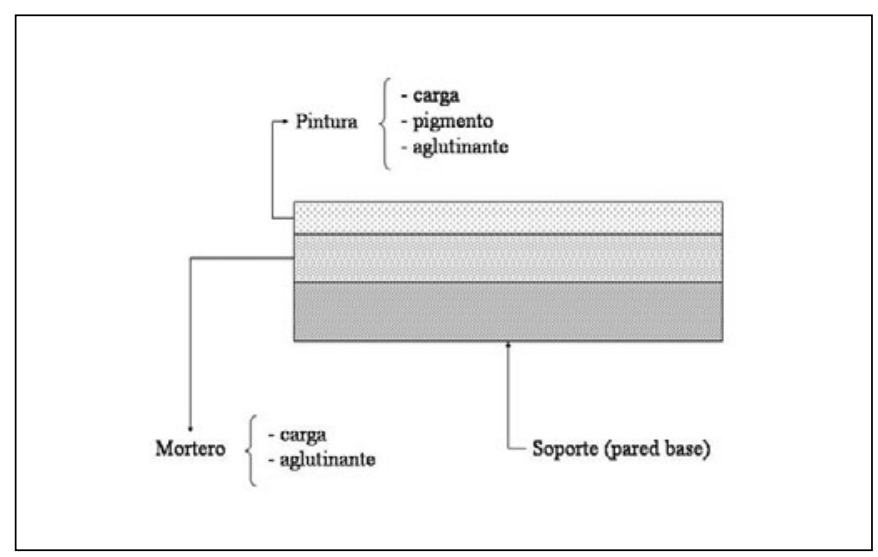

Figura.3: esquema de la sección de una pintura al fresco, tanto para la tumba de Nefertari como para las termas romana.

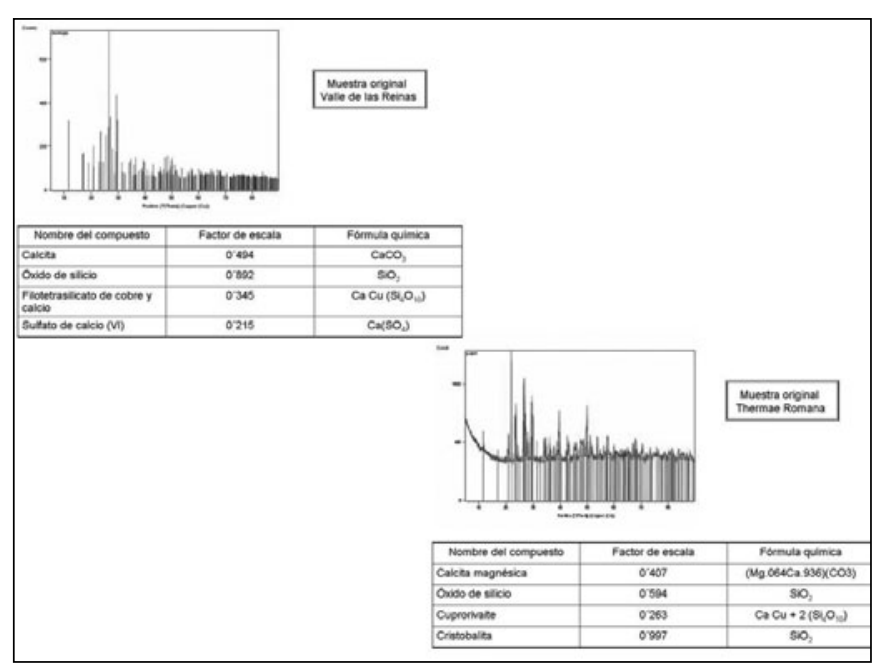

Figura.4: identificación del pigmento de la pintura de la tumba de Nefertari-Merienmut, original del Valle de las Reinas, así como del pigmento de la pintura de las termas romanas; ambas mediante Difracción de Rayos-X, de la capa de pintura exclusivamente.

\section{2.- Muestra del Balneum:}

2.Balneum Pintura (Capa de pintura):

- aglutinante.

- carga.

2.Balneum Mortero (Capa de mortero):

- aglutinante.

- carga.

2.Balneum Pared (Soporte: material de la pared).

Comenzando por la muestra 1 Nefertari, en la capa de Nefertari pintura, encontramos como carga, arena compuesta de cuarzo, silicatos y carbonatos, además, del pigmento azul egipcio (Figura.5). Como se observa en estas figuras, tanto los difractogramas como los análisis EDS-EDX, identifican los distintos materiales que componen la capa de pintura de la tumba de Nefertari- Merienmut. Aparecen cristales de cuarzo, silicatos complejos de sodio, aluminio, etc, y carbonatos de calcio con magnesio minoritario, como carga para el aglutinante y diluyente del pigmento. La presencia de carbonato cálcico tiene el objetivo de dar luminosidad al pigmento de azul egipcio (36). La existencia de sulfato cálcico (yeso), proviene del mortero que hay bajo la pintura, como confirmaremos más adelante al estudiarlo.

El aglutinante utilizado fue la goma arábiga, desleída en agua y adicionada de clara de huevo, típico en la pintura egipcia hasta el uso de la cera (encaústica) (36). No ha podido ser detectada mediante Difracción de Rayos- $X$, pero sí fue detectada por los restauradores de la Getty Conservation Institute (14-16).

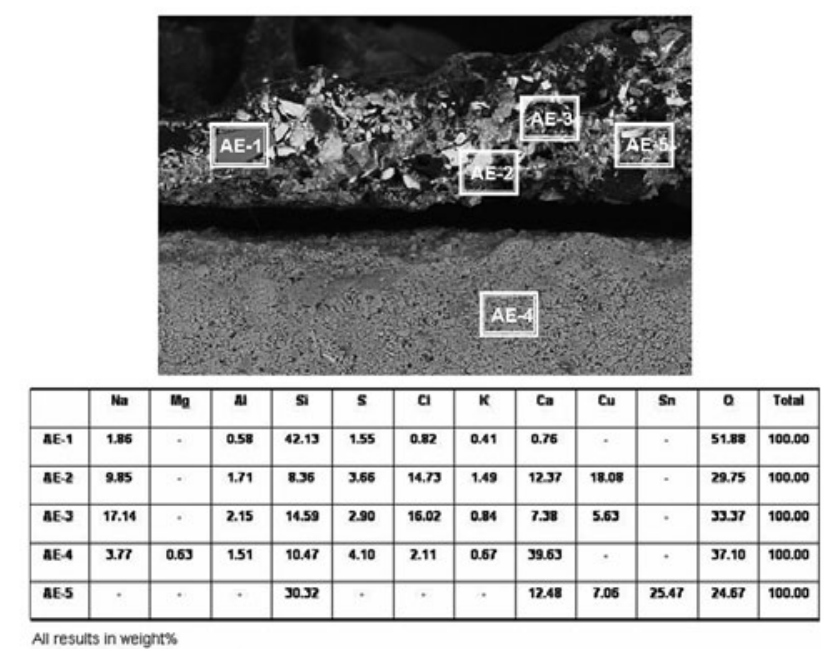

Figura.5: imagen de MEB, con electrones retrodispersados, mostrando la capa de pintura (parte superior) despegada de la pared de roca de la tumba de Nefertari-Merienmut (parte inferior). Los cristales más claros son de pigmento (azul egipcio), el resto, es la arena de la carga (cuarzo, silicatos, carbonatos de calcio) y, la masa envolvente de partículas muy finas es el cemento aglutinante de yeso.

Además, se han marcado los puntos de análisis EDS-EDX con las composiciones de los diferentes cristales de la carga de la pintura: cuarzo (AE-1), silicato (AE-3), pigmento (AE-2) y mortero (AE-4). El cloro es contaminación del agua de desbaste, pulido y filtraciones en la tumba. El punto (AE-5) refleja la presencia de un cristal de silicato mixto de calcio, estaño y cobre en la capa de pintura de la tumba de NeferatiMerienmut. 
La capa de mortero de Nefertari, correspondiente a la muestra de la tumba de Nefertari- Merienmut, es de estuco (yeso) (Figura. 6). Este estuco formado, básicamente por yeso, lleva parte de cal y carga de arena, para darle mayor consistencia y luminosidad al fondo (36). La capa de pintura, va directamente sobre el estuco y éste sobre la pared de roca caliza excavada muy alisada (Figura.3). Esta roca es una caliza microfosilífera formada por esqueletos fósiles de cocolitos tipo Gephyrocapsa Oceanica (Figura. 5 y 7). La roca caliza del Valle de los Reyes y el de las Reinas, en Egipto, se formó en el Eoceno, que comenzó hace 54 millones de años y finalizó hace 40 millones de años. Con un clima de subtropical a cálido, el Sahara egipcio era entonces un mar de poca profundidad perteneciente al océano de Thetis.

El uso en pintura, de materiales para la carga y, el propio pigmento (azul egipcio), muy triturados permite pintar, con brocha y pinceles finos, dibujos y figuras de gran delicadeza y tamaños adecuados, adaptados a la historia que se quería representar en las distintas paredes y techos de la tumba de Nefertari- Merienmut (36). El maestro dibujaba los perfiles de las figuras con pigmento negro (negro de humo) y, después, sus ayudantes iban rellenando de color (coloreando) las imágenes. El color iba desleído con agua, goma arábiga y clara de huevo; utilizándose como recipientes conchas marinas. También la presencia, en la capa de pintura, de carbonato cálcico, pretendía dar una gran luminosidad, lo que se constata desde el primer momento al entrar a la tumba, a pesar de los más de tres milenios que llevan pintadas. El estuco (yeso) como mortero en interiores es muy estable (36); sin embargo, las filtraciones de la roca en el Valle de las Reinas y la humedad ambiental saturante producida por las innumerables visitas desde principios del siglo XX, terminaron por arruinar estas pinturas al fresco que están en distintas fases de restauración (14-16). En la actualidad, las visitas se han restringido notablemente $\mathrm{y}$, en algún caso, se han prohibido en largos periodos de tiempo.

Por último, respecto de la muestra de Nefertari pintura, resaltar que de acuerdo con la literatura internacional (1, 26-35), a partir de la XIX Dinastía, inaugurada con Ramsés

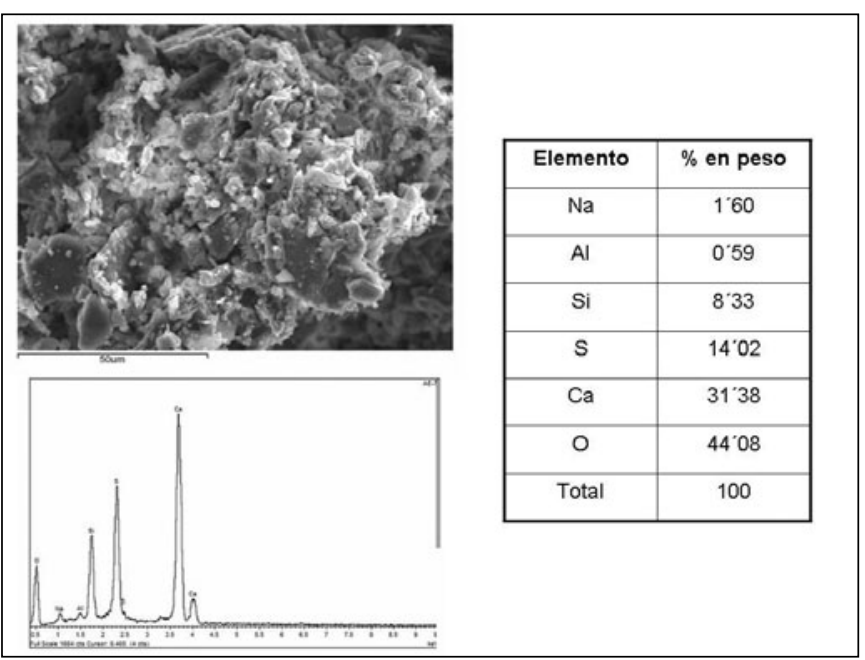

Figura.6: mortero egipcio: se observan cristales de sulfato cálcico (yeso) con algunos de mayor tamaño de cuarzo (carga del mortero de yeso) y carbonato cálcico. En el análisis EDS-EDX del mortero también se detectó el sulfato de calcio, el cuarzo y la cal.
II, esposo de la reina Nefertari- Merienmut, la tecnología de fabricación del azul egipcio cambió, utilizándose como fuente de catión cobre, para la síntesis, el bronce en lugar de óxidos y carbonatos de cobre (cuprita, malaquita, etc), como se venía haciendo desde el comienzo. Esto confirma bastante bien la formulación que describe Marcus Vitrubius Polio en su obra "De Architectura", en el libro (VII,11), en los párrafos dedicados a "Del azul y el amarillo". En él, comenta que se utilizaba en Alejandría, en su época, limaduras de bronce para obtener este hermoso color.

La muestra denominada anteriormente como 2, procedente del Balneum (termas Romanas de Cerro Muriano (Córdoba)), en la capa de Balneum pintura, encontramos como aglutinante al carbonato cálcico y, como carga, arena compuesta de cuarzo, silicatos, etc, además del pigmento azul egipcio (Figura. 8).

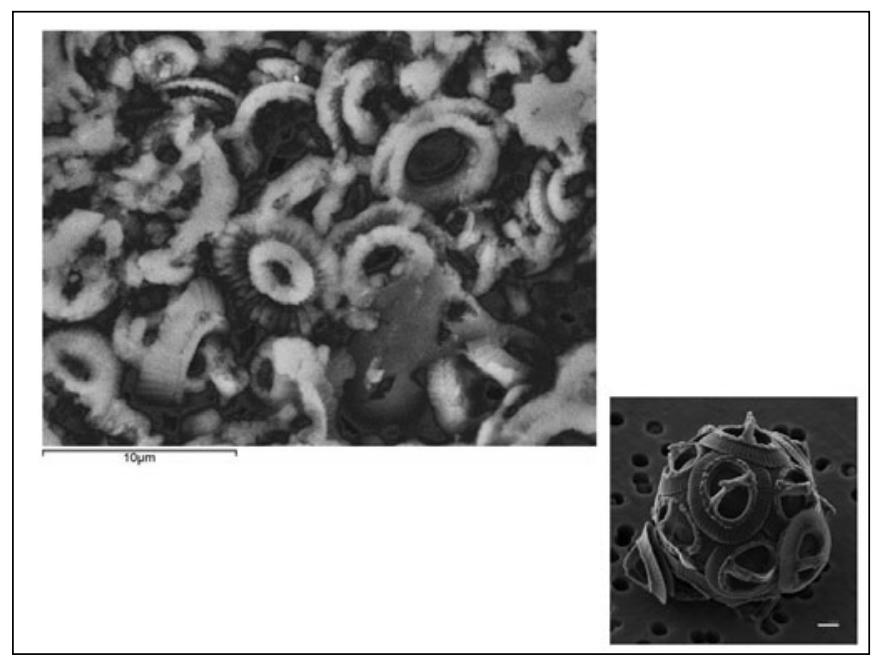

Figura.7: imagen del cocolito del tipo Gephyrocapsa Oceanica, de los que procede la carga y el mortero a base de carbonato cálcico, de la muestra de la tumba de Nefertari-Merienmut; así como un detalle del modelo tridimensional del cocolito Gephyrocapsa Oceanica.

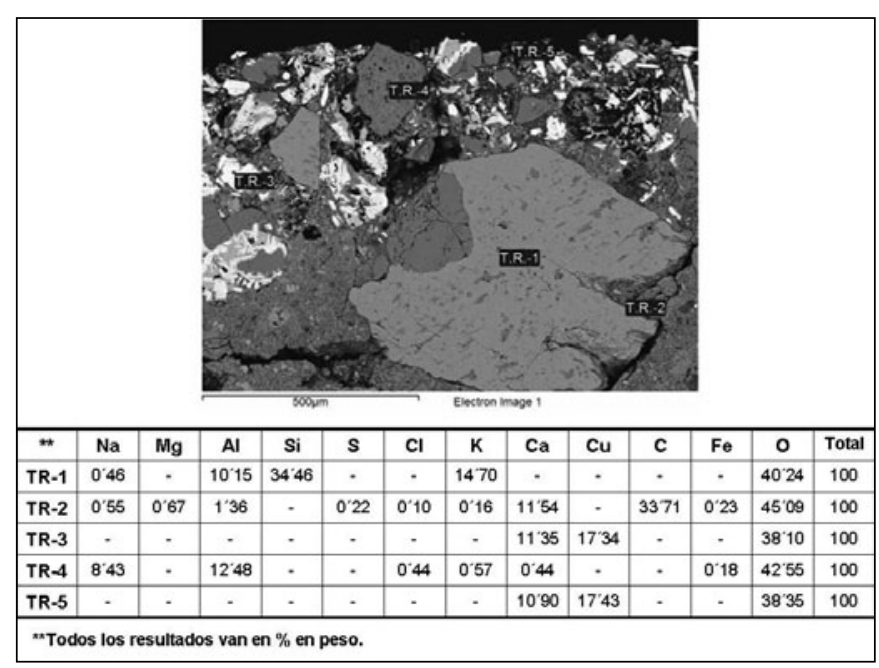

Figura.8: Imagen obtenida mediante electrones retrodispersados en MEB de la capa de pintura de la muestra, denominada 2A, de las termas romanas. Se observan cristales de gran tamaño y de naturalezas diferentes, unidos por un cemento aglutinante muy fino.

En ella se marcan los puntos de análisis EDS-EDX con las composiciones químicas de los diferentes cristales de la pintura: cuarzo (TR-4), silicato (TR-1), carbonato cálcico cemento aglutinante (TR-2) y el pigmento azul egipcio (TR-3 y TR-5). 
Se hacen muy evidentes las diferencias de esta Balneum pintura de la muestra 2 (Balneum, termas romanas) y la Nefertari pintura (tumba de Nefertari- Merienmut) (Figura.7), por el cemento aglutinante de la Balneum pintura, carbonato cálcico y, de la Nefertari pintura, goma arábiga y clara de huevo en agua (Figura. 5). Además, en el caso de la muestra Balneum pintura, el tamaño de las partículas es mucho mayor que en el caso de la Nefertari pintura. En el caso romano, se trata de recubrir grandes zonas, tanto de pinturas de escenas como de paredes completas o secciones de éstas, mientras que en el caso egipcio, se trataba de pintar figuras extremadamente delicadas y de tamaño menor y más preciso y con preponderancia del fino dibujo.

La razón del aglutinante es, en el caso romano, que eran frescos de exteriores o pinturas de interior cotidianas lavables, por lo que se usó el carbonato cálcico, muy estable, a los agentes meteorológicos y/o al lavado. En el caso egipcio, tanto por perseguir una gran finura en el trazo de figuras y jeroglíficos como por ser de interior, se optó por una pintura al fresco sobre yeso (36); usando como diluyente y aglutinante del color goma arábiga desleída en agua con adiciones de clara de huevo.

En la capa Balneum mortero, de la muestra de Balneum (termas romanas), correspondiente al mortero aplicado a la pared de mampostería de los muros de las termas (Figura.3), se ha detectado al carbonato de calcio como aglutinante de ese mortero y, a la carga, como arena compuesta de cuarzo y silicatos (Figura. 9).

El carbonato cálcico de la pintura y mortero romanos es producto de la calcinación (calentamiento a $800^{\circ} \mathrm{C}-900^{\circ} \mathrm{C}$ ) y apagado con agua, de rocas calizas que, posteriormente, se carbonata, pasando a carbonato cálcico durante el secado del mortero y la pintura fresca por el $\mathrm{CO}_{2}$ del aire.

El yeso (sulfato cálcico) de la pintura egipcia es producto de la calcinación del yeso natural (a temperaturas de (120$400)^{\circ} \mathrm{C}$ ) que, posteriormente, durante el secado se rehidrata pasando de nuevo a yeso natural muy estable.

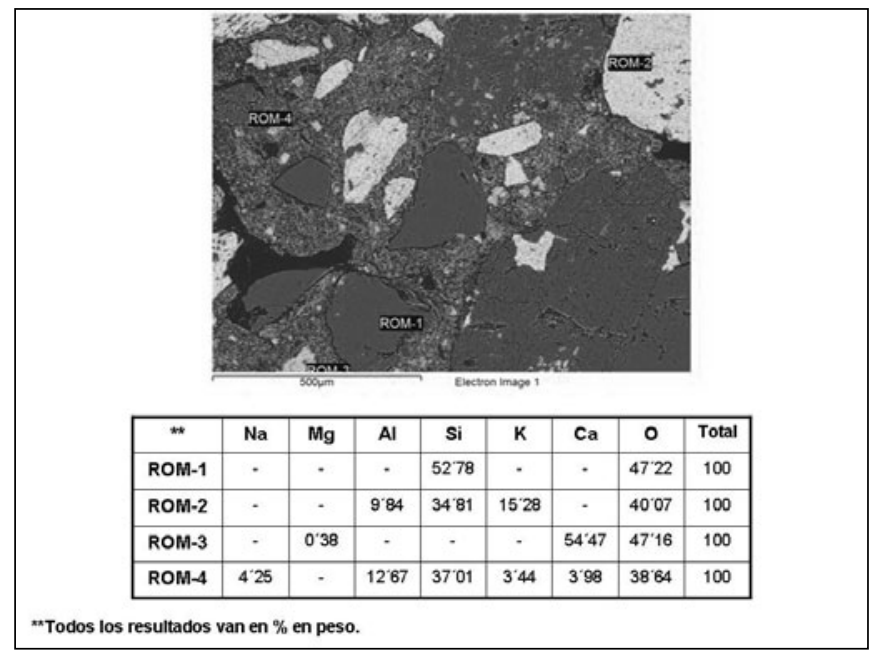

Figura.9: imagen, con electrones retrodispersados, obtenida mediante MEB, de la capa de mortero de la muestra denominada Balneum mortero, de las termas romanas, en la que se marcan los puntos de análisis EDS-EDX con las composiciones químicas de los diferentes componentes del mortero: cuarzo (ROM-1), silicatos (ROM-2 y ROM-4) y el carbonato cálcico como cemento y aglutinante (ROM-3).
Otro detalle fácilmente constatable es el tamaño de las partículas de la carga. En el mortero romano el tamaño de estas partículas es muy grosero. El mortero romano perseguía, directamente, una buena trabazón de la pintura con el mortero de la pared y, una mínima resistencia mecánica que permitiera su limpieza y resistir agresiones de la vida cotidiana y del medio ambiente. En el caso egipcio, el mortero tenía unas intenciones distintas: permitir y facilitar un dibujo y coloreado muy fino y detallista. Se suponía, que esa pintura quedaría encerrada para siempre en su tumba sin ninguna otra servidumbre que la pudiera deteriorar por abrasión, golpes, cambios de humedad, etc. Para aplicar el mortero de estuco, en las pinturas de la tumba de Nefertari- Merienmut, la roca caliza de la pared se alisó convenientemente para conseguir una superficie muy alisada, que permitiera la delicadeza de la pintura egipcia. En el caso de los muros de mampostería (opus quadratum) de las termas Romanas de Cerro Muriano, la roca caliza de la que se extrajeron los bloques es fosilífera; aunque en determinadas zonas se ha producido redisolución de estas calizas y su posterior precipitación como cristales idiomórficos de calcita (Figura. 10). Estos bloques de caliza proceden del Mioceno Superior, periodo que comenzó hace 23’3 millones de años, de la cuenca del Guadalquivir, a cuatro kilómetros del centro de la ciudad de Córdoba, extraídos de las Canteras Romanas del Cerro del Aulagar.

\section{4.- SUMARIO Y CONCLUSIONES}

Con este estudio se ha querido comprobar las diferencias entre las dos pinturas examinadas: muestras de la tumba de la reina egipcia y esposa de Ramses II: Nefertari-Merienmut, y muestras procedentes del Balneum (termas romanas) de Cerro Muriano (Córdoba).

Las diferencias vienen causadas por la funcionalidad de cada uno de los casos estudiados. En el caso de la tumba de la reina Nefertari-Merienmut, se trata de decorar las distintas

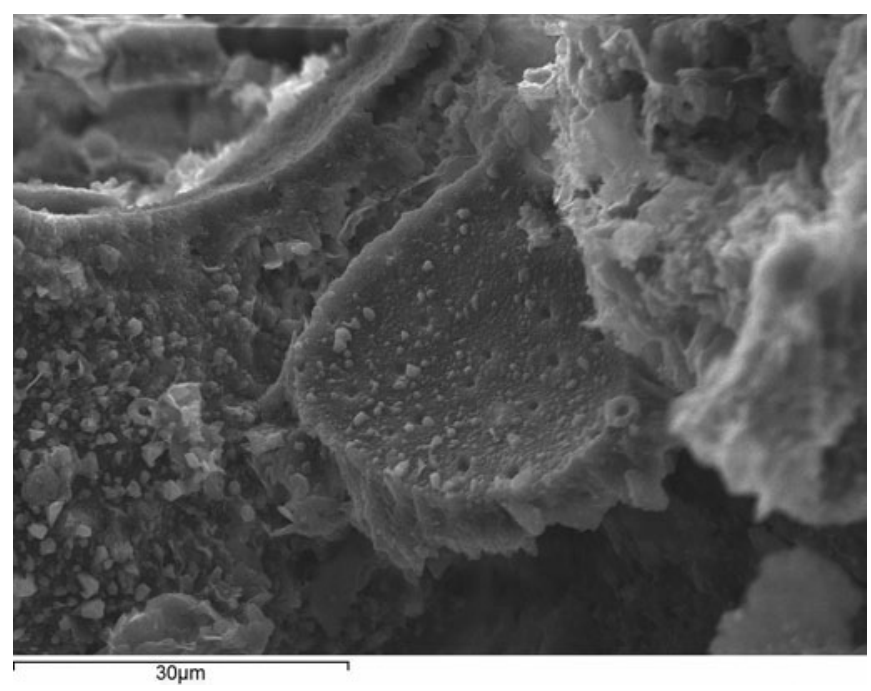

Figura. 10: Micrografía, obtenida mediante MEB, en la que se observan restos de fósiles, aunque muy triturados, pertenecientes a las calizas utilizadas en las termas romanas de Cerro Muriano (Córdoba). 
estancias con dibujos y figuras de gran precisión cuyo objetivo es informar de la vida de la princesa difunta, así como textos sagrados y fórmulas mágicas, válidas para encontrar el más allá y guiar, posiblemente, a su esposo para poderla encontrar tras su muerte. Todo ello realizado en estancias interiores excavadas en la roca, con la previsión de que ningún ser vivo volvería a entrar allí y, por tanto, no sufrirían ningún deterioro. También parecía imposible que el interior de la tumba, herméticamente cerrado, se viera afectado por ningún cambio físico-químico en el ambiente o en las paredes. De alguna manera, así ocurrió en los tres milenios iniciales hasta que, a principios del siglo $X X$, fue descubierta y las multitudinarias visitas crearon microclimas, muy húmedos y perjudiciales, en el interior de la tumba, llegando al 100\% de humedad; suponiendo este hecho la ruina de las pinturas, sin posible comparación con el efecto causado por las filtraciones en las rocas, mucho más lento y menos determinante.

En el caso del Balneum (termas romanas), la funcionalidad de la decoración fue otra. Se trataba de pinturas que debían decorar un ambiente muy húmedo, a veces muy cálido y,

además, estar proyectadas para resistir el deterioro derivado de la actividad de los numerosos seres humanos que emplearían las termas. Sin olvidar que, deberían resistir bien los cuidados de mantenimiento y limpieza, así como el vapor de agua asociado a estos baños.

Todo esto se tradujo en una serie de diferencias derivadas de la funcionalidad de las pinturas en ambos monumentos:

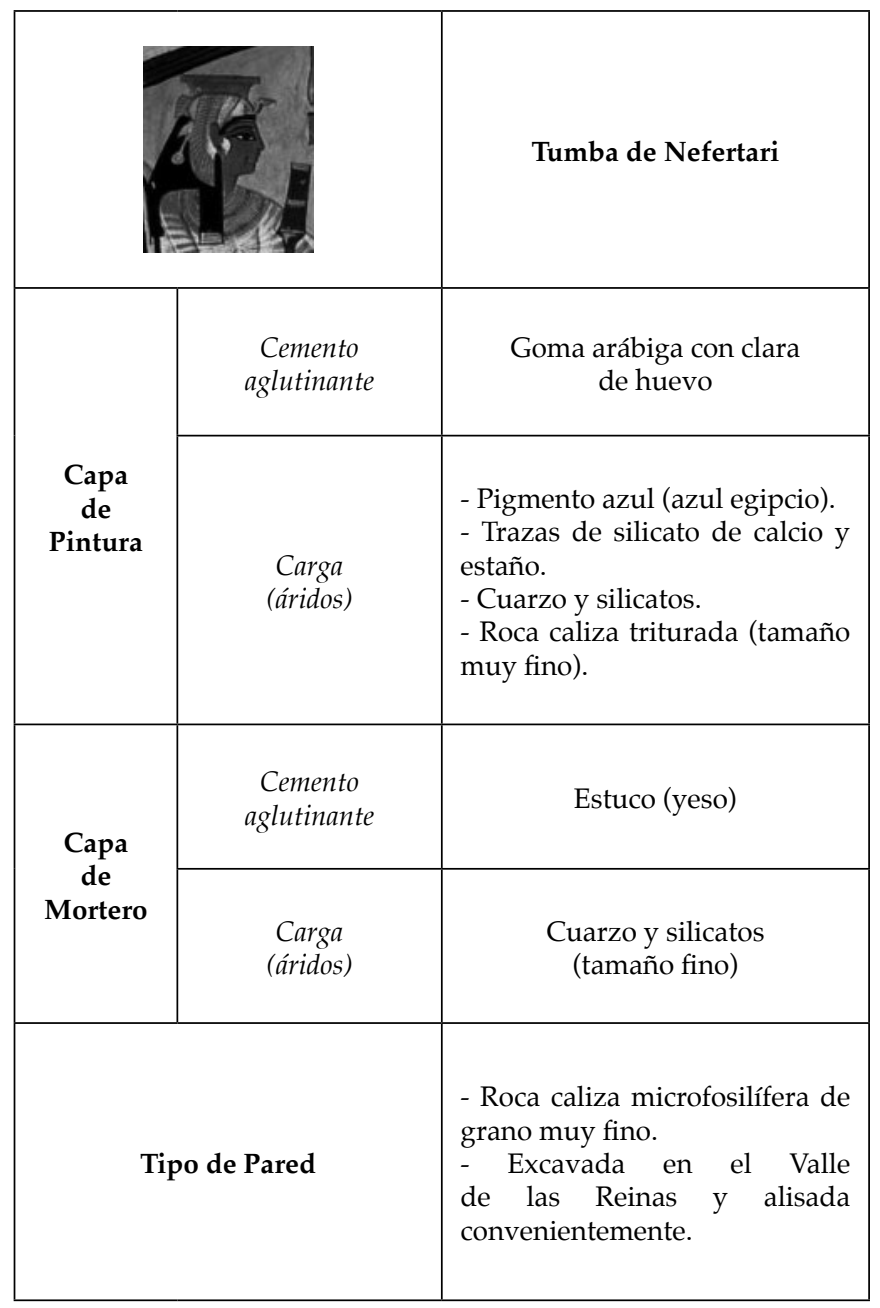

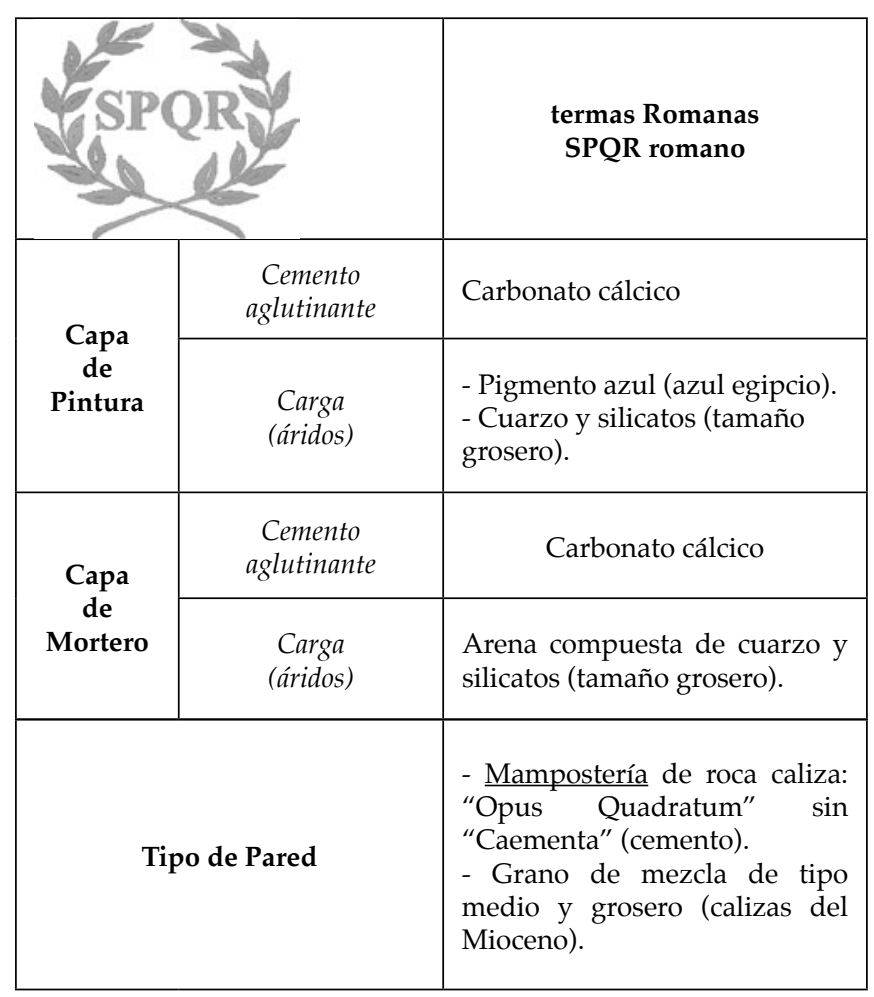

\section{AGRADECIMIENTOS}

Nuestro más sincero agradecimiento a Alfonso y Eugenio, del CAI de Microscopía Electrónica (Luis Bru), y a Julián, del CAI de Difracción de Rayos-X; ambos de la Universidad Complutense de Madrid (U.C.M.)

\section{BIBLIOGRAFIA}

[1] H. Jaksch, W. Seipel, K.L. Weiner, A.E. Goresy: "Egyptian Blue-Cuprorivaite a window to ancient Egyptian technology". Prax. Naturwiss. Chem., 70, Issue 11, 525-535 (1983)

[2] G. Acorsi, G. Verri, M. Bolognesi, N. Armaroli, C. Clementi, C. Miliani, A. Romani: "The exceptional near-infrared luminescence properties of cuprorivaite (Egyptian Blue)". Chem. Commun., 3392-3394 (2009).

[3] J. Riederer: "Egyptian Blue". Artists Pigments: a Handbook of their History and Characteristic, volume 3, E. West Fitzhug (ed.) Oxford University Press: Oxford, 23-45 (1997).

[4] W T. Chase: "Egyptian Blue as a Pigment and Ceramic Material." In Science and Archaeology, edited by R. H. Brill. Cambridge: MIT Press, 80-90 (1971).

[5] M. S. Tite, M. Bimson, and M. R. Cowell: "Technological Examination of Egyptian Blue." In Archaeological Chemistry III, edited by J. B. Lambert. Washington, D.C.: Am. Chem. Soc., 215-242 (1984).

[6] G. Bayer and H.G. Wiedemann. Bildung und Stabilität von Ägyptisch-Blau (Cuprorivait), Prax. Naturwiss. Chem. 62 (2), 181-182 (1975).

[7] G. Bayer and H.G. Wiedemann. Ägyptisch Blau, ein synthetisches Farbpigment des Altertums, wissenschaftlich betrachtet, Sandoz-Bulletin 40, 20-39 (1976).

[8] J. Baines: "Color terminology and color clasification: naciente egyptian color terminology and polychromy". Am. Anthrop. 87, 282-297 (1985).

[9] D. Stulik, E. Porta, A. Palet: "Analices of pigments, binding media and varnishes".

M.A. Corzo, Mahasti Afshar, ed: Arte y la Eternidad: las pinturas murales de Nefertari Proyecto de Conservación, 1986-1992. Los Ángeles: The Getty Conservation Institute, 57-58 (1993).

[10] J.M. Roman, E. Navas: “Considerations about the finding of a fragment of mineral pigment called Egyptian Blue in the site of Cerro de la Mora (Moraleda de Zafayona, Granada, Spain)". Arqueología y Territorio n³, 170 (2006). 
[11] J. Juan-Tresserras: "El uso de plantas para el lavado y teñido de tejidos en época romana. Análisis de residuos de la "fullonica" y la "tinctoria" de "Barcino". Complutum 11, Universidad Complutense de Madrid (Madrid), 245-252 (2000).

[12] L. Garenne-Marot: "Le travail du cuivre dans l'Égypte pharaonique d après les peintures et les bas-reliefs". Paléorient, 11/1, 85-96 (1985).

[13] P. Horne: “Ur and Its Treasures: The Royal Tombs". Expedition, 40, 2, Philadelphia, 4-11 (1998).

[14] Saleh, Saleh Ahmed :"Pigments, plaster and salts analises”. In Wall Paintings of the Tomb of Nefertari, First Progress Report, 94-105 (1987).

[15] P. Mora, L. Mora, G. Capriotti: "Condition survey". In Wall Paintings of the Tomb of Nefertari, First Progress Report, 112-123 (1987).

[16] F. Prensser: "Scientific and technical examination of the tomb of Queen Nefertari at Thelves". The conservation of Wall Paintings. Proceedings of a Symposium organized by the Courtauld Institute of Art and the Getty Conservation Institute. London. July 13-16, 1-12 (1987).

[17] R. Weatherhead, A. Buckley: “Artist' Pigments from Amarna. In ". B. Kemp (Ed.), Amarna Reports V. London: Egyp Exploration Society, 202-239 (1989).

[18] Rehren, Th., Pusch, E.B.: “Late Bronze Age glass production at QantirPiramesses, Egypt". Science 305, 1756-1758 (2005).

[19] B. Gineau: "Albores de la belleza. La pintura romana antigua ". Colores y técnicas. Ars Latina (Ed.), París, 499-516 (1995).

[20] J. Beltrán de Heredia: “Fullonica y tinetoria. Telas, tintes y lavados en la antigua colonia romana. De Barcino a barcinona (siglos I-VII) ". Los restos arqueológicos de la Plaza del Rey de Barcelona (Director arqueólogo: J. Beltrán de Heredia). Museo de Historia de la Ciudad-Ajuntament de Barcelona (Ed.). Barcelona, 48-58 (2001).

[21] R. Calabrés Molina, A.J. Criado Portal, J.A. Martínez García, J.J. Storch de Gracia: "Roman-Era Cooper Production at the Cerro Muriano Smelter". Journal of the Mining, Metals and Materials Society (Springer Sciencies and Business Media). New York.,68-70 (1996).

[22] F. Penco, S. Rodero: "Las termas públicas del yacimiento del Cerro de la Coja: resultados preliminares de la intervención arqueológica de urgencia en el yacimiento de Cerro Muriano (Obejo)". Anuario Arqueológico de Andalucía 2001, Sevilla, 297-316 (2004)

[23] A. Palet i Casas: "Tratado de Pintura: color, pigmentos y ensayo". Ed. de la Universitat de Barcelona. Barcelona, 68-70 (2002)

[24] A.J. Criado, R. Calabrés, J.A. Martínez, J.J. Storch de Gracia: "Metalkundliche untersuchung au kupfer-metall und schlacken ersterfusion ans deu römischen hüttenwerken in Cerro Muriano (Córdoba, Spanien)". Prakt. Metallog., 33(7), 340-349 (1996).

[25] A.J.Criado, R. Calabrés, J.A. Martínez, J.J. Storch de Gracia: “Study of the cooper quality in the extractive metallurgy, during the roman age, at Cerro Muriano (Córdoba, Spain)". Journal of Materials, National Research Council. Washington. September, 68-71 (1996).
[26] M. Uda, S. Sassa, S. Yoshimura, J. Kondo, M. Nakamura, Y. Ban, H. Adachi: "Yellow, red and blue pigmens from ancient Egyptian palace painted walls". Nuclear Instruments and Methods in Physics Research B 161163,758-761 (2000).

[27] G. A. Mazzocchin, D. Rudello, C. Bragato, F. Agnoli: "A short note on Egyptian blue". Journal of Cultural Heritage 5, 129-133 (2004).

[28] K. Hühnerfu $\beta$, A. von Bohlen, D. Kurth: "Characterization of pigments and colors used in ancient Egyptian boat models". Spectrochimica Acta Part B 61, 1224-1228 (2006).

[29] C. Johnson, K. Head, L. Green: "The conservation of a polychrome Egyptian Coffin". Studies in Conservation, 40, No.2. May, 73-81 (1995)

[30] P. Bianchetti, F. Talarico, M.G. Vigliano, M. Fuad Ali: "Production and characterization of Egyptian blue and Egyptian green frit". Journal of Cultural Heritage 1, 179-188 (2000).

[31] M. Uda, M. Nakamura, S. Yoshimura, J. Kondo, M. Saito, Y. Shirai, S Hasegawa, Y. Baba, K. Ikeda, Y. Ban, A. Matsuo, M. Tamada, H. Sunaga, H. Oshio, D. Yamashita, Y. Nakajima, T. Utaka: “'Amarna blue' pinted on ancient Egyptian pottery". Nuclear Instruments and Methods in Physics Research B 189, 382-386 (2002).

[32] G. A. Mazzocchin, F. Agnoli, S. Mazzocchin, I. Colpo: "Analysis of pigments from Roman wall paintings found in Vicenza". Talanta 61, 565572 (2003).

[33] L. Stodulski, E. Farrell, R. Newman: “Identification of Ancient Persian Pigments from Persepolis and Pasargadae". Studies in Conservation, 29, No.3. August, 143-154 (1984).

[34] E. West Fitzhugh, L.A. Zycherman: "An Early Man-Made Blue Pigment from China: Barium Copper Silicate". Studies in Conservation, 28, No.1. Feb., 15-23 (1983).

[35] M. V. Orna, M. J. D. Low, N. S. Baer: "Synthetic Blue Pigments: Ninth to Sixteenth Centuries. I. Literature". Studies in Conservation, 25, No.2. May, 53-63 (1980).

[36] M. Doerner: "Los materiales de pintura y su empleo en el arte". Editorial Reverté,S.A. Barcelona, 236-261 (1975).

[37] J. Barrioa, L. Montealegre, L.A. López Palomo: “Caracterización mineralógica y textural de cerámicas tartésicas de Ategua (Córdoba, España)". Bol. Soc. Esp. Ceram. V. 49, 5, 361-370 (2010).

[38] J.M. Compaña, L. León-Reina, M.A.G. Aranda: "Archaeometric characterization of Terra Sigillata Hispanica from Granada workshops". Bol. Soc. Esp. Ceram. V. 49, 2, 113-119 (2010).

Recibido: $15 / 11 / 2010$

Aceptado: 14/6/2011 